\title{
Pseudoporphyria in a Peritoneal Dialysis Patient
}

Cutaneous changes can be observed in patients with endstage renal disease (ESRD). The most common findings are half-and-half nails, pruritus, xerosis, and cutaneous hyperpigmentation. Pseudoporphyria is a rare disease resembling porphyria cutanea tarda both clinically and pathologically (1). Factors involved in the etiology of pseudoporphyria include ultraviolet exposure, hemodialysis, and use of non-steroidal anti-inflammatory drugs, antibiotics, and diuretics (2). Although pseudoporphyria is seen in $13 \%$ of hemodialysis patients, it is rare in peritoneal dialysis (PD) patients (3). Here, we present a PD patient who developed pseudoporphyria after sun exposure.

\section{CASE DESCRIPTION}

A 71-year-old female presented with erythema and bullous lesions on both arms and hands that had not responded to self-administered topical steroids. She had been on PD for 10 years because of chronic glomerulonephritis. Her medications included amlodipine, sevelamer, calcitriol, atorvastatin, folic acid, and erythropoietin. She stated that she had had intense sun exposure before developing the skin changes. She denied taking any other medication. Physical examination revealed erythema, blisters, and crusted lesions on the dorsal aspects of the hands and forearms. The laboratory findings are presented in Table 1. Based on the history of sun exposure and characteristic skin lesions, a dermatologist diagnosed pseudoporphyria. The patient refused a skin biopsy. Oral $\mathrm{N}$-acetyl cysteine (NAC) treatment was initiated. After 3 weeks, the skin lesions had resolved completely (Figure 1).

TABLE 1

Patient Laboratory Results

\begin{tabular}{lc}
\hline \multicolumn{1}{c}{ Laboratory test } & Result \\
\hline Blood urea nitrogen & $73 \mathrm{mg} / \mathrm{dL}$ \\
Creatinine & $8.7 \mathrm{mg} / \mathrm{dL}$ \\
Sodium & $137 \mathrm{mEq} / \mathrm{L}$ \\
Potassium & $4.1 \mathrm{mEq} / \mathrm{L}$ \\
Total protein & $6 \mathrm{~g} / \mathrm{dL}$ \\
Albumin & $3.9 \mathrm{~g} / \mathrm{dL}$ \\
Calcium & $10.7 \mathrm{mg} / \mathrm{L}$ \\
Phosphorus & $3.6 \mathrm{mg} / \mathrm{dL}$ \\
White blood cells & $9,100 / \mu \mathrm{L}$ \\
Hemoglobin & $13.9 \mathrm{~g} / \mathrm{dL}$ \\
Hematocrit & $44 \%$ \\
Platelets & $241,000 / \mu \mathrm{L}$ \\
Parathyroid hormone & $402 \mathrm{pg} / \mathrm{L}$ \\
Alanine aminotransferase & $27 \mathrm{mEq} / \mathrm{L}$ \\
Aspartate transaminase & $22 \mathrm{mEq} / \mathrm{L}$ \\
Ferritin & $252 \mathrm{mg} / \mathrm{dL}$ \\
C-reactive protein & $3.7 \mathrm{mg} / \mathrm{L}$ \\
\hline
\end{tabular}




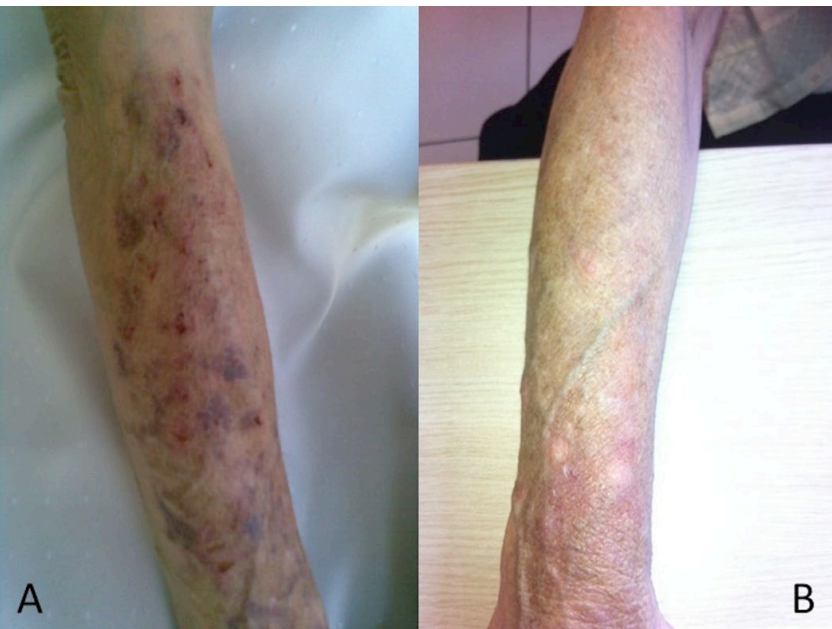

Figure 1-A) Distal arms, extending from the end of the shirt sleeves show erythematous, blistering lesions in the PD patient. B) Complete resolution of skin lesions after $\mathrm{NAC}$ therapy. $\mathrm{PD}=$ peritoneal dialysis; $\mathrm{NAC}=\mathrm{N}$-acetyl cysteine.

The treatment was stopped after 6 weeks. One year later, the patient was re-admitted with similar skin lesions, which she stated developed following sun exposure again. This time, hydroxychloroquine was initiated and resulted in complete resolution of the skin lesions.

\section{DISCUSSION}

Pseudoporphyria is a photodistributed vesiculobullous disorder with similarities to porphyria cutanea tarda (4), differing from the latter by the normal porphyrin profile (2). The relationship between pseudoporphyria and ESRD is unclear. Although the porphyria profile is altered, showing increased plasma uroporphyrin levels, in ESRD patients, pseudoporphyria does not develop in every patient. Furthermore, pseudoporphyria can also be observed in dialysis patients with normal plasma porphyria levels. Pseudoporphyria is reported more frequently in hemodialysis patients than in PD patients. This may be related to the lower plasma porphyrin levels in PD patients compared with that in hemodialysis patients (5). Therefore, some wonder whether there is a need to measure the porphyrin levels in ESRD patients.

Sun exposure is an important trigger for pseudoporphyria, as was the case in our patient. It is necessary to investigate whether an additional photosensitizing factor, such as a medication, is required for overt disease. There are reports of pseudoporphyria due to coexisting hemodialysis and photosensitizing medication exposure or hemodialysis and ultraviolet exposure. In fact, erythropoietin might have been responsible for aggravating the photosensitivity in our patient. Glutathione deficiency resulting from sun exposure and oxidative stress might also be responsible for the development of pseudoporphyria (6). N-acetyl cysteine increases the intracellular glutathione biosynthesis in this setting (7), and its long-term use is beneficial in the treatment of pseudoporphyria. Indeed, we successfully treated our patient with 6 weeks of NAC $(4,8)$. Anti-malarial drugs are also recommended in resistant and recurrent cases (9).

In conclusion, clinicians should be aware of skin changes after sun exposure in PD patients. Pseudoporphyria is recognizable and treatable, but requires an expert opinion. We recommend that all dialysis patients avoid or protect themselves from intensive sun exposure.

\section{DISCLOSURES}

The authors have no financial conflicts of interest to declare.

Arzu Velioglu ${ }^{1}$

Tulin Ergun ${ }^{2}$

Cetin Ozener ${ }^{1}$

Department of Internal Medicine, Division of Nephrology ${ }^{1}$

Department of Dermatology ${ }^{2}$

Marmara University, School of Medicine

Istanbul, Turkey

*email: arzuvelioglu@gmail.com

\section{REFERENCES}

1. Schanbacher CF, Vanness ER, Daoud MS, Tefferi A, Su WP. Pseudoporphyria: a clinical and biochemical study of 20 patients. Mayo Clin Proc 2001; 76(5):488-92.

2. Green JJ, Manders SM. Pseudoporphyria. J Am Acad Dermatol 2001; 44(1):100-8.

3. ChazotC, ChazotI, Charra B, TerratJC, Vanel T, Calemard E, et al. Functional study of hands among patients dialysed for more than 10 years. Nephrol Dial Transplant 1993; 8(4):347-51

4. Felix RH, Silva MF Jr, Almeida JB, Neto PB. Pseudoporphyria associated with hemodialysis. Kidney Int 2011; 79(1):140.

5. Glynne P, Deacon A, Goldsmith D, Pusey C, Clutterbuck E. Bullous dermatoses in end-stage renal failure: porphyria or pseudoporphyria? Am J Kidney Dis 1999; 34(1):155-60.

6. Lomaestro BM, Malone M. Glutathione in health and disease: pharmacotherapeutic issues. Ann Pharmacother 1995; 29(12):1263-73.

7. Holdiness MR. Clinical pharmacokinetics of $\mathrm{N}$-acetylcysteine. Clin Pharmacokinet 1991; 20(2):123-34.

8. Guiotoku MM, Pereira Fde P, Miot HA, Marques ME. Pseudoporphyria induced by dialysis treated with oral $\mathrm{N}$-acetylcysteine. An Bras Dermatol 2011; 86(2):383-5

9. El Kabbaj D, Laalou A, Alouane Z, Bahadi A, Oualim Z. Hemodialysisassociated pseudoporphyria resistant to $\mathrm{N}$-acetylcysteine. Saudi J Kidney Dis Transpl 2011; 22(2): 311-4.

doi: $10.3747 /$ pdi.2014.00309 